\title{
実験的片開き䅡椎管拡大術における応力の分布と構造上の安定 一有限要素解析法による検討
}

\author{
Stress Distribution and Construct Stability in an Experimental Cervical Open-Door Laminoplasty Model \\ -Three-dimensional Finite Element Analysis-
}

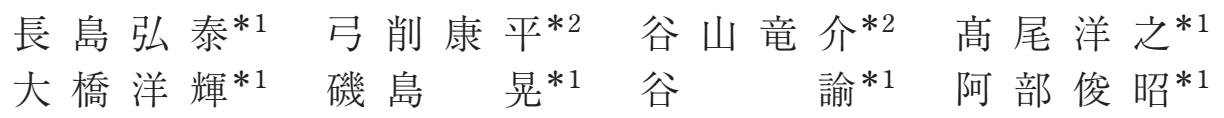

Hiroyasu Nagashima, M.D., Kohei Yuge, Ph.D., Ryusuke Taniyama, Hiroyuki Takao, M.D.,

Hiroki Ohashi, M.D., Akira Isoshima, M.D., Satoshi Tani, M.D., Toshiaki Abe, M.D.

\begin{abstract}
Background : Open-door cervical laminoplasty requires devices such as stay sutures (SS), laminar spacers (LS), and titanium mini-plates (TM) to keep the elevated lamina open. However, the significance and differences in the effects of each of these devices remain unclear. This study aimed at investigating the role of these devices, using a 3-dimensional finite element (FE) model.

Methods : An FE bone model of the fifth cervical vertebra was constructed. Its lamina was elevated by guttering at the hinge site, simulating an open-door technique (G model). SS, LS, and TM were added to the G model, simulating laminoplasty with SS (SS model), LS (LS model), and TM (TM model), respectively. Compression loading force was applied to the elevated lamina in 2 directions of the horizontal plane, and the stress distribution response was analyzed.

Results : The peak Mises stress which integrates the stresses in multiple directions into a unified vector was concentrated at the hinge region in the G and SS model. In the LS and TM model, the peak Mises stresses were observed in the connecting regions between the LS and the lateral mass, and the TM and the elevated lamina, respectively. The Mises stress in the hinge region was minimal in the LS model. Moreover, the bony peak Mises stress and the maximum deformation were minimal in the LS model.

Conclusions : This stress distribution study clearly demonstrated that the placement of artificial implants such as LS and TM determined the stress concentration at the hinge region during laminoplasty with SS. The results of deformation studies showed that LS was best for stabilizing the elevated lamina. Based on this analysis, we suppose that the use of LS for stabilization of the hinge region might yield favorable results over other devices in open-door laminoplasty.
\end{abstract}

(Received : September 27, 2012 ; accepted : March 6, 2013)

\section{Key words}

cervical spine, open-door laminoplasty, laminar spacer, finite element model, stress distribution

*1 東京慈恵会医科大学脳神経外科 $/$ T105-8461 港区西新橋 3-25-8〔連絡先：長島弘泰〕

Address reprint requests to : Hiroyasu Nagashima, M.D., Department of Neurosurgery, Jikei University School of Medicine, 3-25-8 Nishishinbashi, Minato-ku, Tokyo 105-8461, Japan

$* 2$ 成蹊大学理工学部 

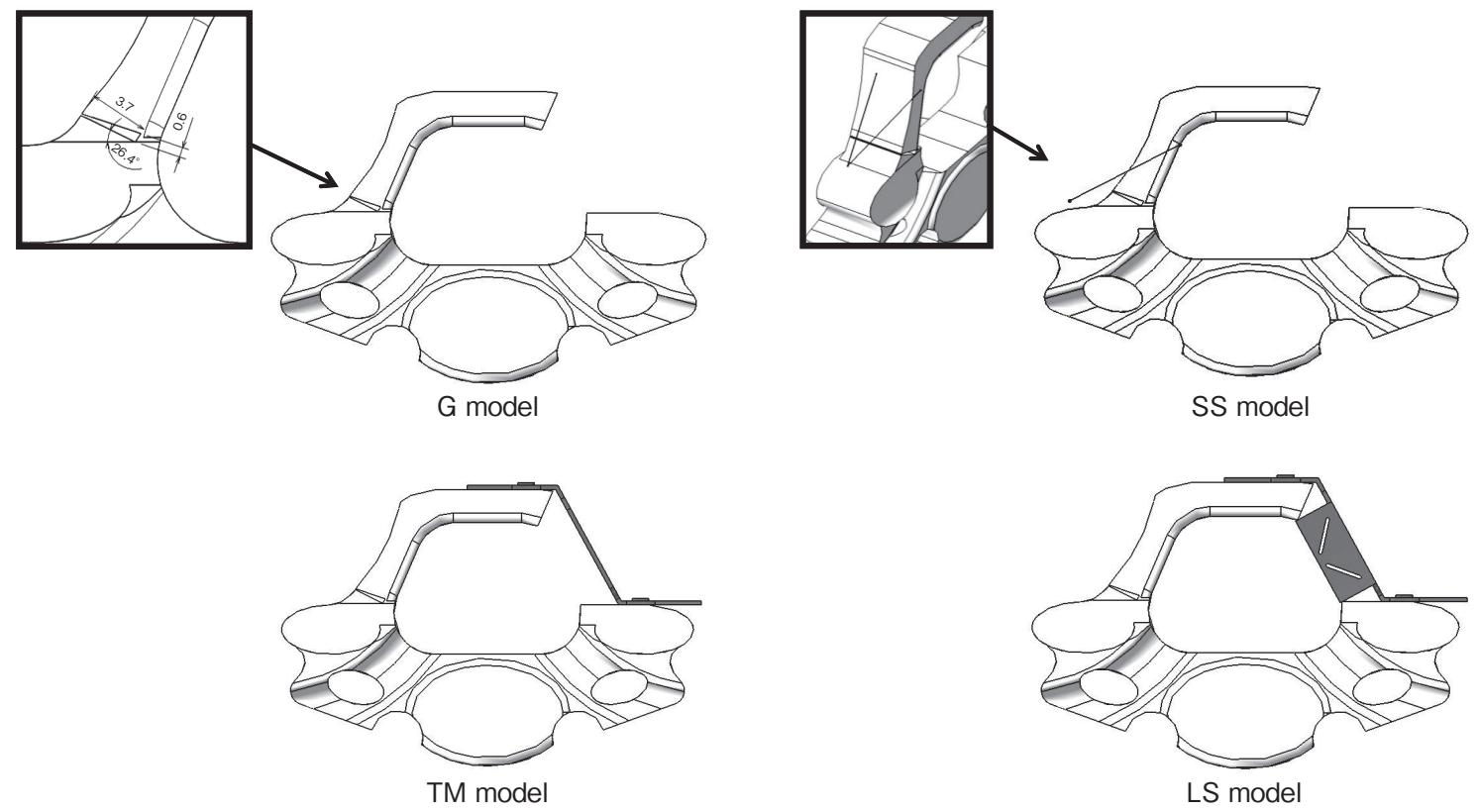

Fig. 1

A three-dimensional model of the C5 vertebra with elevated lamina in an open-door fashion : G model with gutters ; SS model with stay sutures ; TM model with titanium mini-plates ; and LS model with laminar spacers.

\section{緒 言}

澒椎症性脊髄障害の手術療法の 1 つとして「片開き頚 椎管拡大術」が平林ら ${ }^{11} に よ り 1977$ 年に開発されて以 来,わが国はもとより諸外国においても expansive opendoor laminoplasty と呼ばれて広く行われるようになり， その変法, 改良法が数多く報告されている2 12). それら の方法に扔ける根本的な相違点の 1 つとして, 椎弓の挙 上を維持する方法の違いが挙げられる。

平林らの原法は, laminar spacer (LS) や titanium miniplate (TM) などの人工移植物を使用せず, stay suture (SS) を用いて椎弓の挙上を保つものである ${ }^{10,13,14)}$. 最近では 同様な目的で anchor screw などを使用した文献が散見 され，現在も LS などを使用しない同術式の有効性が報 告されている3,4,13,15). ほかの大部分の手術法は, 挙上椎 弓の再閉鎖予防のためにLSを使用して扔り，そのうえ で挙上椎弓の安定や良好な骨癒合を目的とした LS の材 質や形状の変更, 最近では軸性疼痛の軽減や澒椎可動性 の維持を目的とした後澒筋群の温存などの変法が報告さ れている ${ }^{6,7,16 \sim 19)}$. 一方, TM で挙上椎弓を維持する方法 は, 挙上椎弓と外側塊の間にできる間隙に TM を設置 し, 挙上椎弓端と外側塊にスクリューで固定する方法で あり，スクリュー固定による安定性と操作の簡便性が特 徴である ${ }^{2,7 \sim 9,20)}$. これらの手術方法の有用性を臨床的に 検討した報告は多いが, 挙上椎弓の維持法の違いがもた
らす基礎的な構造力学上の相違を検討した研究はきわめ て少ない.

そこでわれわれは, SS, TM, LS を用いた片開き䅡椎 管拡大術の構造力学上の相違を比較検討することを目的 として，3 次元有限要素解析モデル (3D finite element model：FEM）を用いた解析を行った。本稿では, 挙上 椎弓に負荷を加えた際の, 椎弓や TM, あるいは LS に 生じた応力分布の変化から, それぞれの構造力学上の相 違について検討し, 報告されている臨床結果と比較し考 察した。

\section{対象および方法}

今回使用した FEM は第 5 頝椎の模型より作製し，そ の椎弓を片開き法で挙上した（Fig. 1).このモデルの蝶 番部の骨に幅 $0.6 \mathrm{~mm}$, 深さ $3.7 \mathrm{~mm}$, 水平より 26.4 度の 切り込みを入れ, gutter を作成したものを $\mathrm{G}$ モデルとし た. SS に使用する縫合糸のモデル化には, 長さに対して 断面が非常に小さい物体の解析を行う際に用いられる ビーム要素を用い, 直径が $0.5 \mathrm{~mm}$ のチタン製と設定し た。この縫合糸モデルを挙上椎弓に 2 本取り付け, 外側 塊上に他端をボール支持（並進自由度を拘束, 回転自由 度は自由）で固定したものを SS とし，SSを用いた片開 き澒椎管拡大術後における蝶番の骨癒合前の状態を想定 した. $\mathrm{G}$ モデルに TM を装着したモデルを $\mathrm{TM}$ モデルと 

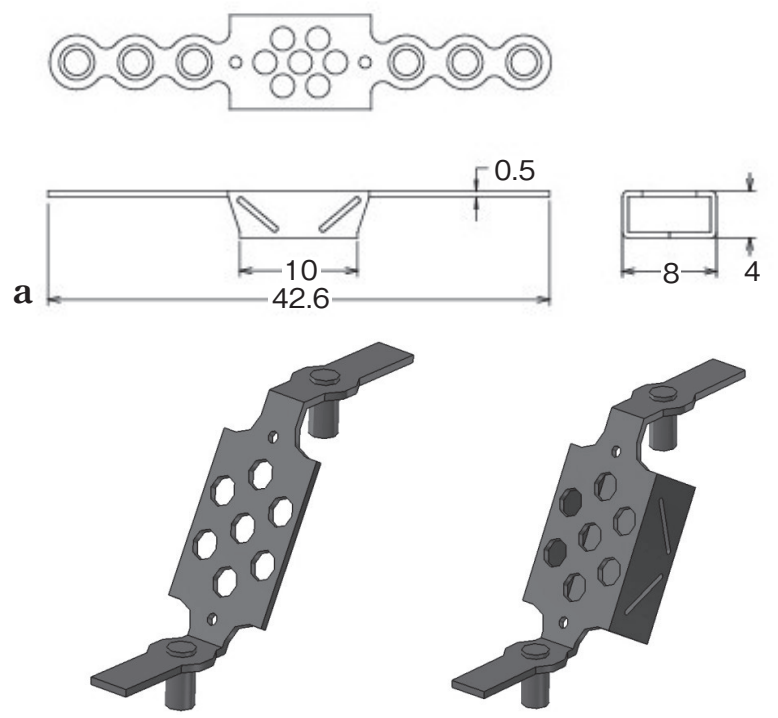

b

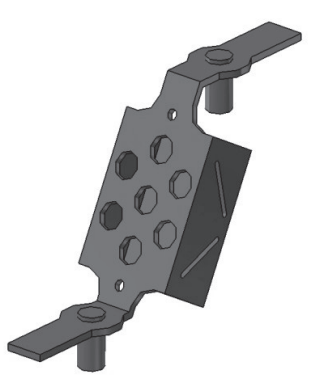

C

Fig. 2 A schematic view of the implant

a : Schematic representation of the actual implant (Laminoplasty Basket) demonstrating a cage with small apertures and 2 arms.

b : A mini-plate made by removal of the cage from the laminar spacer.

c : Laminar spacer simulating Laminoplasty Basket.

し，TM を用いた片開き頚椎管拡大術後における蝶番の 骨癒合前の状態を想定したＧモデルにチタン製 LS を 使用したモデルを LS モデルとし，LS を使用した片開き 頚椎管拡大術後に打ける蝶番の骨癒合前の状態を想定し た. 使用した LS の材質は ELI チタン (extra low interstitial elements titanium) で, 形状は Fig. 2 a に示した (Laminoplasty Basket: L-Basket; Ammtec, Tokyo) ${ }^{19)}$. また，TM は L-Basket のスペーサー部分を除去して作 成した（Fig. 2 b). TM 㧍よびLSのスクリュー部分は一 体化させた。スクリューは骨モデルに小孔を開けて「ボ ルト結合拘束」を行った。拘束条件に関し，骨とスク リュー結合部は「軸一致」と「ボルト締め付け結合」(締 め付け力 $15 \mathrm{~N})$, 骨とプレートの接触面は「一致」と「面 接触」とした。これらのモデルを要素に分割し, 骨, TM, LS に生じる応力と変位を解析した，FEM の作成と解析 にはコンピューターソフトウェア CATIA（ARGO GRAPHICS Inc., Tokyo）を用いた。

使用した骨とチタンの材料特性は Table 1 に示した。 荷重条件は, $\mathrm{x}$ 方向に $5 \mathrm{~N}, \mathrm{y}$ 方向に $-2 \mathrm{~N}$, 大きさ $5.385 \mathrm{~N}$ の分布荷重を骨にかけたものを横荷重, $\mathrm{y}$ 方向に一6N の 分布荷重を与えたものを上荷重とした $($ Fig. 3).この荷 重は $600 \mathrm{~g}$ 弱の抢もりを挙上椎弓上に置いた程度のもの であり，日常生活で生じ得る負荷を想定した。
Table 1 Material properties of titanium and bone

\begin{tabular}{lll}
\hline & Titanium & \multicolumn{1}{c}{ Bone } \\
\hline Young modulus $\left[\mathrm{N} / \mathrm{m}^{2}\right]$ & $1.14 \mathrm{e}+11$ & $8.75 \mathrm{e}+9$ \\
Poisson's ration & 0.36 & 0.261 \\
Density $\left[\mathrm{kg} / \mathrm{m}^{3}\right]$ & 4,460 & 1,456 \\
Thermal expansion $[\mathrm{Kdeg}]$ & $9.5 \mathrm{e}-6$ & $2.36 \mathrm{e}-5$ \\
Yield strength $\left[\mathrm{N} / \mathrm{m}^{2}\right]$ & $8.25 \mathrm{e}+8$ & $4.18 \mathrm{e}+7$ \\
\hline
\end{tabular}

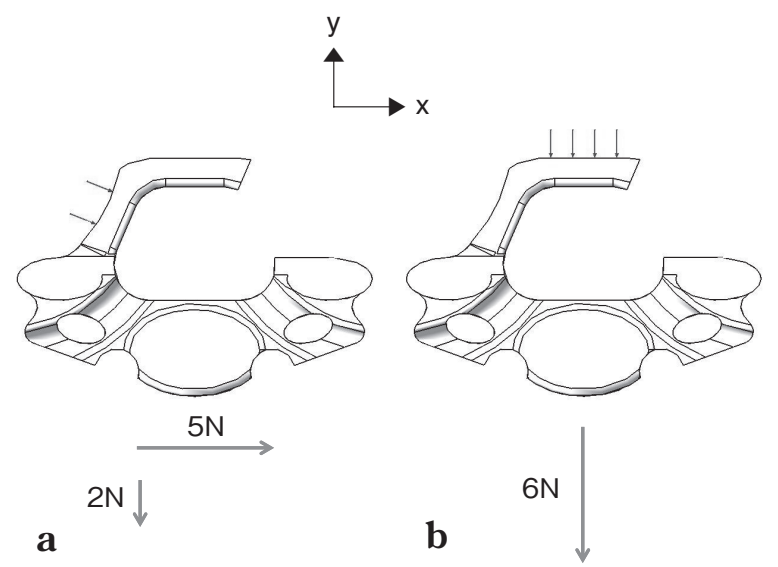

Fig. 3 Loading force of the elevated lamina a : Oblique compression.

b : Direct compression.

Table 2 Peak Mises stress and maximum deformation in each model

\begin{tabular}{|c|c|c|c|c|}
\hline & & \multicolumn{2}{|c|}{$\begin{array}{c}\text { Peak Mises } \\
\text { stress }[\mathrm{MPa}]\end{array}$} & \multirow{2}{*}{$\begin{array}{c}\text { Maximum } \\
\text { deformation } \\
{[\mathrm{mm}]}\end{array}$} \\
\hline & & Bone & TM/LS & \\
\hline \multirow{4}{*}{$\begin{array}{l}\text { Oblique } \\
\text { compression }\end{array}$} & G model & 14.4 & & 0.116 \\
\hline & SS model & 2.55 & & 0.022 \\
\hline & TM model & 3.04 & 13.3 & 0.00793 \\
\hline & LS model & 2.18 & 8.26 & 0.00403 \\
\hline \multirow[t]{4}{*}{ Direct compression } & G model & 33.4 & & 0.300 \\
\hline & SS model & 11.5 & & 0.114 \\
\hline & TM model & 3.20 & 40.3 & 0.00841 \\
\hline & LS model & 1.50 & 8.08 & 0.00385 \\
\hline
\end{tabular}

\section{結 果}

横荷重および上荷重に対する各モデルの最大 Mises 応力と最大変位を Table 2 に示す. Mises 応力とは, 負荷 によって物質内に生じる多方向の応力を一軸化した数值 である。ここで留意すべき点は，TM モデルと LS モデ ルはボルト接合拘束を行っているため，これらのモデル 同士の最大 Mises 応力の単純比較は可能だが，これらの モデルと G モデルや SS モデルの最大 Mises 応力の単 純比較はできないことである、G モデルと SS モデルの 最大 Mises 応力の単純比較は可能である。また, SS モ 

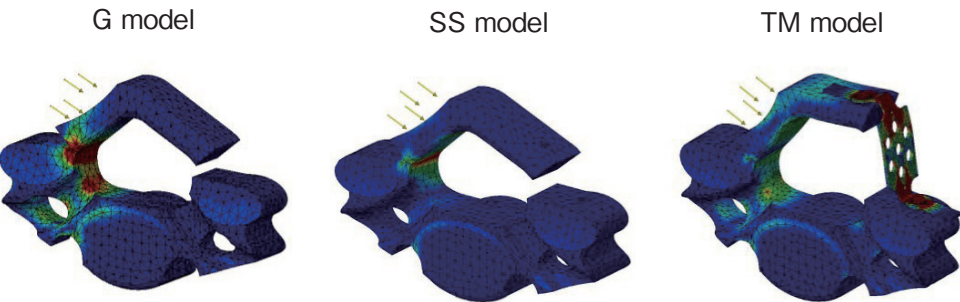

Oblique compression
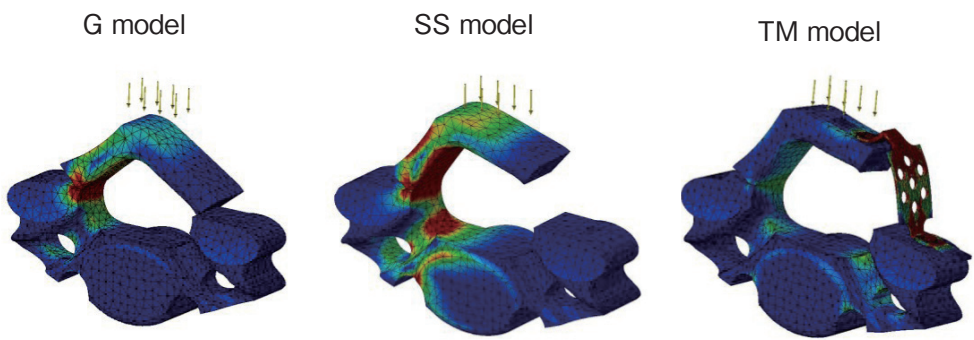

Direct compression
[Pa]

$2.5 \mathrm{e}+006$

$2.25 \mathrm{e}+006$

$2 \mathrm{e}+006$

$1.75 e+006$

$1.5 e+006$

$1.25 \mathrm{e}+006$

$1 \mathrm{e}+006$

$7.5 \mathrm{e}+005$

$5 \mathrm{e}+005$

$2.5 \mathrm{e}+005$

504

[Pa]

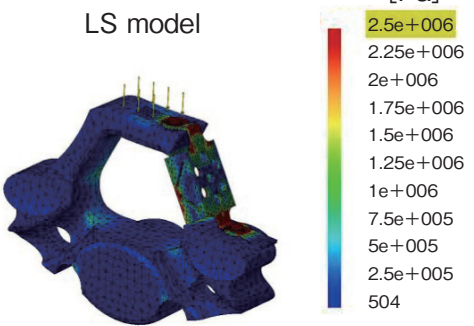

Fig. 4

The Mises stresses in the C5 vertebra. Peak stresses of 28.6 MPa and 14.1 MPa were observed in the hinge region of the G model under oblique and direct compressive loading, respectively. Corresponding peak stresses of $11.5 \mathrm{MPa}$ and $2.55 \mathrm{MPa}$ were observed in the hinge region of the SS model ; 39.4 MPa and 31.5 MPa, in the region connecting the TM with the elevated lamina in the TM model ; and $17.5 \mathrm{MPa}$ and $16.6 \mathrm{MPa}$, in the region connecting the LS with the lateral mass in the LS model.
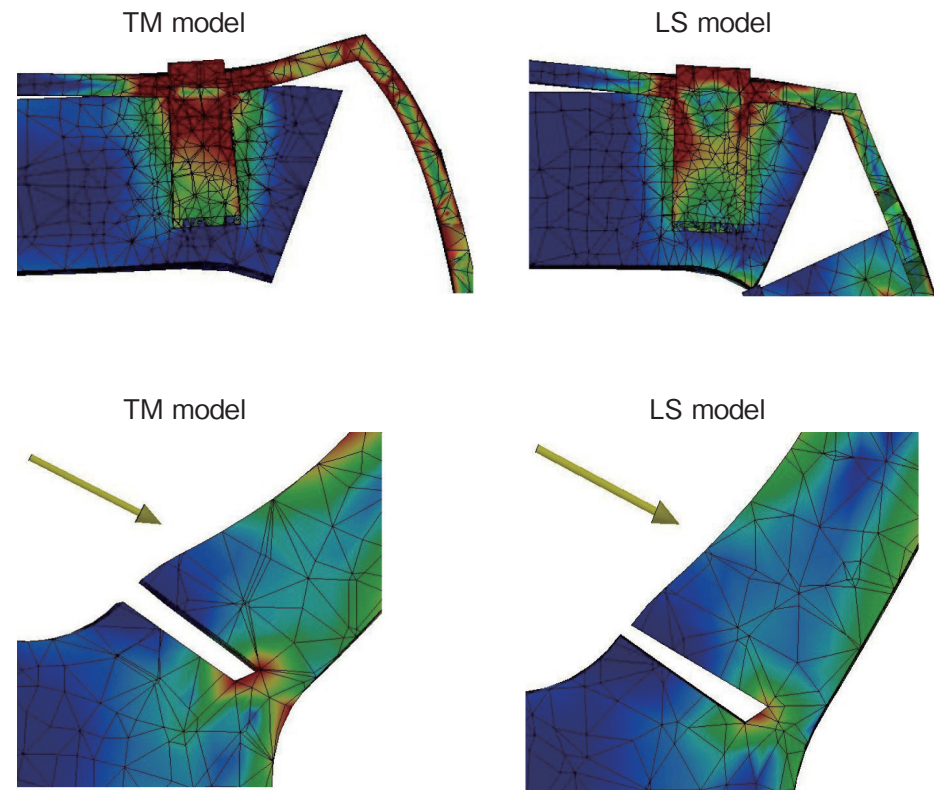

LS model

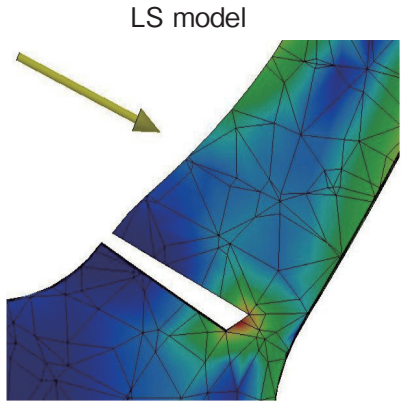

$3 e+006$

$2.7 e+006$ $2.4 \mathrm{e}+006$ $2.1 \mathrm{e}+006$ Fig. 5

$1.8 \mathrm{e}+006$ A detailed sectional view of the elevated lamina $1.2 \mathrm{e}+006$ and an inserted screw in the TM and LS model 9 e+005 showing greater stress at the screw in the TM $6 e+005$ model than in the LS model, and the deformation $3 \mathrm{e}+005$ is to make the screw backout in the TM model.
デルの解析は骨の応力のみであり, 牽引糸や外側塊上の 固定部の応力は含まれていない. G モデルと SS モデル を比較すると, 最大 Mises 応力, 最大変位はともに SS モデルで減少し，特に横荷重における骨の応力の減少は 著明であった。 TM モデルと LS モデルを比較すると， LS モデルの最大 Mises 応力, 最大変位はともに減少し,
特に上荷重で LS 内に生じる応力の減少は著明であっ た。最大変位において LS モデルは横荷重, 上荷重とも に最小であった。

それぞれの荷重における応力分布図を Fig. 4 に示す. これらの図における横荷重に対する変形は，G モデルで 100 倍に, SS モデル，TM モデルと LS モデルは 500 倍 
に増幅し明瞭化した。また，上荷重に対する変形は $\mathrm{G}$ モ デル， SS モデルで 50 倍に，TM モデルと LS モデルは 500 倍に増幅し明瞭化した. Mises 応力の分布をみると, G モデルと SS モデルでは横荷重, 上荷重ともに蝶番付 近に集中し, 最大 Mises 応力は蝶番部で生じた. TM モ デルと LS モデルでは蝶番部の応力集中が抑制され, $\mathrm{TM}$ モデルでは挙上椎弓と TM の結合部に, LS モデルで は外側塊と LS の結合部に最大 Mises 応力が生じた。横 荷重に扔ける挙上椎弓とスクリューの断面図では，TM モデルでは LS モデルよりスクリュー付近に応力が集中 し，変形によってスクリューを引き抜く力が加わってい た（Fig. 5)。また，蝶番部の断面図にて，TM モデルの 蝶番部には LS モデルより高い応力分布を認めた（Fig. 6).

\section{考 察}

数值解析法の 1 つである有限要素解析の医学への応 用は, 1970 年代より試みられ ${ }^{21)}$, その後コンピューター 技術の発展に伴う急速な解析能力の向上により, 頭部外 傷の発生メカニズムの解明などに用いられている22 25). 脊椎脊髄分野でも，この手法は instrumentationにおける 強度解析, また䅡䯣損傷や腰椎分離すべり症のメカニズ ムの解明などに応用されている26 28). しかし, 片開き澒 椎管拡大術の際の挙上椎弓における力学的負荷などの解 析に扔いて，本手法はほとんど応用されていない.

今回使用した解析モデルにおいて, 蝶番部の応力分布 は TM や LS の有無により顕著に変化した，G モデルと SS モデルでみられた明らかな蝶番部への応力集中は, ほ かのモデルでは認めなかった。本解析では, 率引系をチ タン製の直径 $0.5 \mathrm{~mm}$ と設定しており, 実際より強固な ものとして評価した。また，牽引系の支持点も固定とし たが，実際には支持点も負荷に応じて移動することが予 想される。より強固に挙上椎弓を固定したと考えられる モデルにおいて, 蝶番部に応力が集中した結果は, SS を 用いた術式に扔ける合併症として蝶番の破綻をきたしや すいことを示唆している。臨床報告でも, Satomi ら ${ }^{29)}$ は 204 例中 4 例の蝶番落下による上肢運動障害を報告し, これらの症例の中にはスペーサーを使用しない術式が含 まれている。また, Yonenobu ら ${ }^{30)}$ は, 手術時における gutter 作成の際に, 椎弓の可動性を確認しながら注意深く 掘削することの重要性を強調しており, 今回の解析は, それを裏付ける結果といえる。

また, 挙上椎弓の閉鎖は, SS を用いた術式における問 題点の 1 つであり, 術後早期合併症としての報告が散見
される1,2,18,31,32). 今回の結果においても, TM や LS の使 用により挙上椎弓の安定性がきわめて高くなることは, 負荷に対する TM モデルと LS モデルの最大変位が SS モデルより著明に減少したことから明らかである。しか し, 今回の解析モデルに扔いて, LS 非使用手術における 挙上椎弓の閉鎖が臨床上の問題になるかどうかは不明で ある。臨床報告において Matsumoto ら ${ }^{13)}$ は, LS 非使用 症例において術後 3 力月まで挙上椎弓は徐々に閉鎖し たがそれ以降は安定したと報告しており, 蝶番の骨癒合 後には椎弓の安定が得られることを示唆している。

一方, TM と LS を使用した場合, 荷重による応力は これらと骨との接合部に集中した。特に TM モデルで挙 上椎弓断端の接合部に, 結合を外そうとする力が働くこ とが今回の解析で明らかになった.臨床的にも Rhee ら7) は, TM を用いた片開き法を報告し, 椎弓側のスクリュー の離脱が $2.3 \%$ に生じ，スクリューを 2 個装着すること で離脱を予防し得たと報告しており, 今回の結果と符合 する，さらに今回の解析では，LS を使用することで，こ のスクリュー部分と蝶番部に生じる応力分布はともに軽 減されることが示唆された。よって, LS 使用手術は, よ り優れた挙上椎弓の維持と蝶番の安定が期待できる.

今回使用したモデルは 1 つの椎体のみを使用したシ ンプルなものであり, ゆえに, 挙上椎弓の維持法の違い による応力の変化を解明する目的において, 明瞭な結果 を得ることができた. Tadepalli ら ${ }^{33)} も, 1$ 椎体の片開き頚 椎管拡大術モデルを屍体澒椎と FEM にて作成し, 挙上 椎弓への荷重実験の結果, FEM の生体力学的解析の有用 性を報告している。しかし, 本モデルは, 澒椎の屈曲, 伸展, 回旋などによる応力の解析には適さず, また, 澒 椎高位により椎体・椎弓の形状が異なる点を考慮してい ないなど, 実際の症例に即していない点があり, 今後の 課題であると考える.

\section{結 語}

片開き頚椎管拡大術の FEM において, SS を用いたモ デルでは応力は蝶番部に集中し，TM や LS の使用によ り蝶番部の応力は著明に減少した. TM を使用した場合, 挙上椎弓と $\mathrm{TM}$ との接合部に応力が集中し, 同部のスク リューが離脱するような変位を認めた. LS の使用により 挙上椎弓との接合部の応力分布は減少し, 変位も最小で あった. よって LS は, 挙上椎弓の維持という本来の目 的以外に, 蝶番を安定させる効果をもつと考えた。 


\section{文 献}

1) Hirabayashi $\mathrm{K}$, Watanabe $\mathrm{K}$, Wakano $\mathrm{K}$, et al : Expansive opendoor laminoplasty for cervical spinal stenotic myelopathy. Spine $8: 693-699,1983$

2) Roselli R, Pompucci A, Formica F, et al : Open-door laminoplasty for cervical stenotic myelopathy : surgical technique and neurophysiological monitoring. J Neurosurge 92:38-43, 2000

3) Wang HQ, Mak KC, Samartzis D, et al : "Spring-back" closure associated with open-door cervical laminoplasty. Spine J 11 : 832-839, 2011

4) Chen HC, Chang MC, Yu WK, et al : Lateral mass anchoring screws for cervical laminoplasty : preliminary report of a novel technique. J Spinal Disord Tech 21:387-392, 2008

5) Yang SC, Niu CC, Chen WJ, et al : Open-door laminoplasty for multilevel cervical spondylotic myelopathy: good outcome in 12 patients using suture anchor fixation. Acta Orthop $\quad 79: 62^{-}$ 66, 2008

6) Praharaj SS, Vasudev MK, Kolluri VR, et al : Laminoplasty : an evaluation of 24 cases. Neurol India $48: 249-254,2000$

7) Rhee JM, Register B, Hamasaki T, et al : Plate-only open door laminoplasty maintains stable spinal canal expansion with high rates of hinge union and no plate failures. Spine $36: 9-14$, 2011

8) Park AE, Hellar, JG : Cervical laminoplasty : use of a novel titanium plate to maintain canal expansion - surgical technique. J Spinal Disord Tech $17: 265-271,2004$

9) O'Brien MF, Peterson D, Casey AT, et al : A novel technique for laminoplasty augmentation of spinal canal area using titanium miniplate stabilization. A computerized morphometric analysis. Spine 21:474-483, 1996

10) Vitarbo E, Sheth RN, Levi AD : Open-door expansile cervical laminoplasty. Neurosurgery $\quad 60$ : S154-159, 2007

11) Herkowitz $\mathrm{HN}:$ Cervical laminaplasty : its role in the treatment of cervical radiculopathy. J Spinal Disord 1:179-188, 1988

12) Herkowitz $\mathrm{HN}$ : A comparison of anterior cervical fusion, cervical laminectomy, and cervical laminoplasty for the surgical management of multiple level spondylotic radiculopathy. Spine $13: 774-780,1988$

13) Matsumoto $M$, Watanabe $K$, Tsuji $T$, et al : Risk factors for closure of lamina after open-door laminoplasty. J Neurosurg Spine 9:530-537, 2008

14) Hirabayashi K, Miyakawa J, Satomi K, et al : Operative results and postoperative progression of ossification among patients with ossification of cervical posterior longitudinal ligament. Spine $6: 354-364,1981$

15) Iwasaki M, Okuda S, Miyauchi A, et al : Surgical strategy for cervical myelopathy due to ossification of the posterior longitudinal ligament: Part 1 : Clinical results and limitations of laminoplasty. Spine $32: 647-653,2007$

16) Tani S, Isoshima $A$, Nagashima $H$, et al : Laminoplasty with preservation of posterior cervical elements: surgical technique. Neurosurgery $50: 97-101,2002$

17) Tanaka N, Nakanishi K, Fujimoto $Y$, et al : Expansive lamino- plasty for cervical myelopathy with interconnected porous calcium hydroxyapatite ceramic spacers : comparison with autogenous bone spacers. J Spinal Disord Tech 21:547-552, 2008

18) Hosono N, Sakaura H, Mukai Y, et al : En bloc laminoplasty without dissection of paraspinal muscles. J Neurosurg Spine 3:29-33, 2005

19) Tani S, Suetsuna F, Mizuno J, et al : New titanium spacer for cervical laminoplasty: initial clinical experience. Technical note. Neurol Med Chir (Tokyo) 50 : 1132-1136, 2010

20) Chen G, Luo Z, Nalajala B, et al : Expansive open-door laminoplasty with titanium miniplate versus sutures. Orthopedics 35: e543-548, 2012

21) Ward CC, Thompson RB : The development of a detailed finite element brain model. Proc. 19th STAPP Car Crush Conf. 641674, 1975

22）村上成之，中村紀夫，西本哲也，他：側頭部衝撃におけるび まん性脳損傷の発生機序についての一考察一二次元有限要素 法を用いた脳内応力分布の検討から．神経外傷 $22: 110$ 116, 1999

23) Nishimoto $\mathrm{T}$, Murakami S: Relation between diffuse axonal injury and internal head structures on blunt impact. $J$ Biomech Eng 113 : 140-147, 1998

24）高尾洋之，村上成之，西本哲也，他：有限要素法モデルを用 いた脳挫傷の発生メカニズム. 交通科研資 48:77-78, 2007

25) Watanabe D, Yuge K, Nishimoto $T$, et al : Simulation of a human head subject to a lateral rotational impact and study on the cause of a diffuse axonal injury. Int J Vehicle Safety 5 : 333-344, 2011

26) Puttlitz CM, Goel VK, Traynelis VC, et al : A finite element investigation of upper cervical instrumentation. Spine $\mathbf{2 6}$ 2449-2455, 2001

27) Imajo $\mathrm{Y}$, Hiiragi I, Kato $\mathrm{Y}$, et al : Use of the finite element method to study the mechanism of spinal cord injury without radiological abnormality in the cervical spine. Spine 34 : E8387, 2009

28）西良浩一：腰椎分離症一Spinal surgeon が知っておくべき State of the Art. 春䯣外科 25：119-129，2011

29) Satomi K, Ogawa J, Ishii $Y$, et al : Short-term complications and long-term results of expansive open-door laminoplasty for cervical stenotic myelopathy. Spine J 1 : 26-30, 2001

30) Yonenobu K, Oda T: Posterior approach to the degenerative cervical spine. Eur Spine J 12 (Suppl 2)：195-201, 2003

31) Kaminsky SB, Clark CR, Traynelis VC : Operative treatment of cervical spondylotic myelopathy and radiculopathy. A comparison of laminectomy and laminoplasty at five year average follow-up. Iowa Orthop J 24:95-105, 2004

32) Okada M, Minamide A, Endo T, et al : A prospective randomized study of clinical outcomes in patients with cervical compressive myelopathy treated with open-door or French-door laminoplasty. Spine $34: 1119-1126,2009$

33) Tadepalli SC, Gandhi AA, Fredercks DC, et al : Cervical laminoplasty construct stability : an experimental and finite element investigation. Iowa Orthop J 31 : 207-214, 2011 